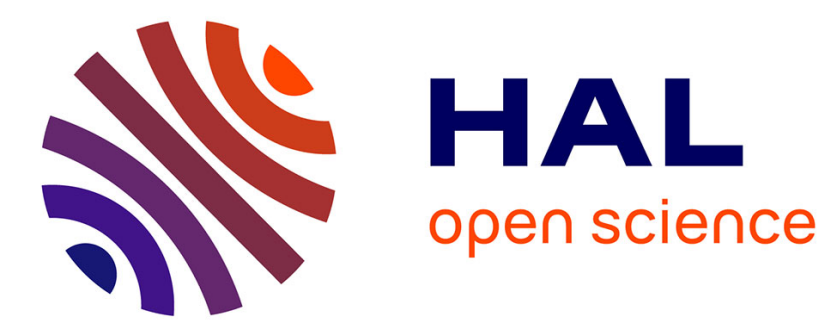

\title{
Experimental investigations of swollen nitrile rubber under fatigue loading
}

Mei Sze Loo, Andri Andriyana, Jean-Benoit Le Cam, Eric Robin

\section{To cite this version:}

Mei Sze Loo, Andri Andriyana, Jean-Benoit Le Cam, Eric Robin. Experimental investigations of swollen nitrile rubber under fatigue loading. European Conference on Constitutive Models for Rubber IX, Sep 2015, Prague, Czech Republic. hal-01136560

\section{HAL Id: hal-01136560 https://hal.science/hal-01136560}

Submitted on 6 May 2020

HAL is a multi-disciplinary open access archive for the deposit and dissemination of scientific research documents, whether they are published or not. The documents may come from teaching and research institutions in France or abroad, or from public or private research centers.
L'archive ouverte pluridisciplinaire HAL, est destinée au dépôt et à la diffusion de documents scientifiques de niveau recherche, publiés ou non, émanant des établissements d'enseignement et de recherche français ou étrangers, des laboratoires publics ou privés. 


\title{
Experimental investigations of swollen nitrile rubber under fatigue loading
}

\author{
M.S. Loo \& A. Andriyana \\ Department of Mechanical Engineering, University of Malaya, Kuala Lumpur, Malaysia
}

J.-B. Le Cam \& E. Robin

Institut de Physique de Rennes, UMR CNRS 6251, Université de Rennes 1, Rennes Cedex, France

\begin{abstract}
In diesel engine fuel system, the rubber components such as gaskets and hoses are usually made of nitrile rubber. In such application, the rubber components are exposed to aggressive solvent, i.e. diesel fuel. While the compatibility of elastomers in the conventional diesel has long been established, their compatibility in biodiesel remains incompletely understood. Indeed, the intense study on biodiesel as alternative source of energy has increased tremendously since the existing fossil fuels are no longer considered as feasible due to their ever increasing cost, their continuous diminution in supply and environmental concerns. Furthermore, the abundant feedstock of biodiesel such as palm biodiesel in Southeast Asia along with the existing tropical climate has favoured further research works in this field. During the service, rubber components are usually subjected to cyclic loading for a long term duration (fatigue loading). From the standpoint of replacing conventional diesel with biodiesel, it is necessary to study and to compare the fatigue performance of rubber exposed to biodiesel and conventional diesel. The present study investigates the fatigue damage in swollen nitrile rubber due to exposure to biodiesel and conventional diesel. Swollen nitrile rubber specimens are obtained through stress-free immersion tests in palm biodiesel (B100) and conventional diesel fuel (B0) to attain the same degree of swelling. The uniaxial fatigue tests are subsequently conducted on both dry and swollen rubbers. Field Emission Scanning Electron Microscopy (FESEM) analysis is carried out to observe the fracture surfaces. Stretch-N curves are plotted to illustrate the fatigue life duration. It is found that the swollen B100 rubber has a shorter lifetime than the swollen B0 rubber. FESEM micrographs revealed that the loading conditions have no effect on the crack initiation and propagation patterns regardless of the swelling state.
\end{abstract}

\section{INTRODUCTION}

Conventional petroleum-derived fuels are no longer seen as a futuristic source of fuel because of its ever increasing cost and continuous diminution. This condition has driven researchers to explore intensively the prospects of biofuels as a renewable energy alternative for the current depleting energy resources. Their technical advantages besides being eco-friendly have attracted a large number of interests among researches to investigate continuously its properties, potentials and applications (Gray et al. 2006; Demirbas 2008; Fazal et al. 2011). The biodiesel is anticipated to be replacing fossil diesel (Demirbas 2008).

Rubber acquires their own unique traits which enables it to be widely utilized for the diesel engine fuel system. During the service, rubber components are usually subjected to cyclic loading for a long term duration (fatigue loading). While the introduction of biodiesel such as palm biodiesel is proven to be environmentally friendly, the compatibility between biodiesel and elastomeric components remains as a major challenge up to this date. Most of the previous research works have intensely investigated the fuel system compatibility of the elastomer in the biodiesel compared to the conventional diesel (Demirbas 2008; Fazal et al. 2011; Haseeb et al. 2011; Alves et al. 2013). A large number of these compatibility studies explored only the different types of physical property changes such as the mass, hardness and tensile strength change. The quality of ignition and stability are also studied to identify the factor prohibiting the full compatibility of biodiesel in engine fuel system. Yet, the molecular or microscopic changes induced in the elastomer due to the diffusion of diesel and biodiesel are not widely investigated.

The very few number of study in fractographic study of fatigue effects at these scales are reported for filled natural rubber (Saintier 2000; Le Cam et al. 2008; Le Cam et al. 2013) and filled styrene 
butadiene rubber (Le Cam et al. 2014). To the best knowledge of authors, the most recent investigation is reported for swollen elastomers (Loo et al. 2015). The present work investigates the mechanical response of nitrile rubber swollen by palm biodiesel under fatigue loading conditions. As comparison, the fatigue characteristics of elastomers swollen by conventional diesel fuel is also investigated.

\section{EXPERIMENTAL PROGRAMME}

The material investigated is a commercial grade of carbon black-filled natural rubber with 60 shore hardness and $25 \mathrm{wt} \%$ of carbon-black. The diabolo rubber specimens have a height, outer diameter, and wall thickness of $55 \mathrm{~mm}, 25 \mathrm{~mm}$, and $6 \mathrm{~mm}$ respectively. The swollen rubber specimens are obtained by immersing dry specimens in diesel and biodiesel for 90 days and 10 days respectively to achieve a $5 \%$ volume change. The swelling level $J_{s}$ denotes the volume ratio of the swollen rubber. No standard is followed regarding the choice of the specimens of immersion durations.

In order to verify that the swollen rubbers maintained its swelling state throughout the fatigue test, the mass for swollen rubbers are measured before and after testing. This is done similarly for the hardness with the intention to investigate the effect of different swelling level on the physical properties of the swollen rubber. The hardness is measured with a Shore A hardness tester with a deviation of $\pm 1 \mathrm{HA}$. The mass and hardness change for both swollen and dry rubbers are calculated with the following equations:

$$
\begin{gathered}
\Delta M=\frac{M_{i}-M_{s}}{M_{s}} \times 100 \\
\Delta H=\frac{H_{i}-H_{s}}{H_{s}} \times 100
\end{gathered}
$$

where $\Delta M$ is the change in mass, $M_{i}$ is the mass in air of the swollen rubber after testing, $M_{s}$ is the mass in air of the swollen rubber before testing, $\Delta H$ is the percentage of change in hardness, $H_{i}$ is the hardness value of the swollen rubber after testing and $H_{s}$ is the hardness value of the swollen rubber before testing.

In the current investigation, $R_{\varepsilon}$ is the loading ratio in terms of strain or the nominal strain loading ratio. It is defined as the ratio between the minimum $\left(\varepsilon_{\min }\right)$ and the maximum $\left(\varepsilon_{\max }\right)$ strain levels applied to the specimen. The loading condition here corresponds to the repeated uniaxial tension, so $R_{\varepsilon}$ is equal to zero. The dry and swollen rubbers were subjected to four levels of maximum stretch at room temperature: 1.5, 1.6, 1.75, 1.9 and 2 .
The imposed frequency for all loading condition is $1 \mathrm{~Hz}$ except for the maximum stretch of 1.5 where a $2 \mathrm{~Hz}$ frequency is applied. These values of frequencies are chosen so that they would not induce significant thermal effect and are compatible to machine capacity.

\section{RESULTS AND DISCUSSION}

\subsection{Hardness and mass change}

The measured average hardness and mass values for all specimens before and after fatigue testing are tabulated in Table 1 and Table 2 respectively. The negative sign in the percentage shows that there is a decrease in hardness and mass for swollen rubbers. The decrease in mass for both is less than $0.5 \%$ which suggests that the rubber retains its degree of swelling throughout the tests with no significant amount of liquid secreted out. From the Table 1 it is observed that the exposure of rubber to solvents leads to a decrease in the hardness. Indeed, the immersion of rubbers in solvents may lead to the extraction of fillers or additives (Graham et al. 2006; Trakarnpruk and Porntangjitlikit 2008; Seehra et al. 2012; Richaud et al. 2013). The oxidation process eventually induces chain scission and decreases the polymer resistance to failure (Richaud et al. 2013). Similarly, Haseeb et al. (2010) described that the diffusion of the biodiesel into the NBR attacks the polymer backbone through macromolecule chain scission. Therefore, this mechanism could be attributed to the decrease of hardness in swollen rubbers before and after testing. After undergoing fatigue loading, further decrease in the hardness is observed: $9 \%$ in swollen

Table 1. Hardness values of dry and swollen rubbers before and after fatigue test.

\begin{tabular}{llll}
\hline Rubber & $\begin{array}{l}\text { Before } \\
\text { testing }(\mathrm{H})\end{array}$ & $\begin{array}{l}\text { After } \\
\text { testing }(\mathrm{H})\end{array}$ & $\begin{array}{l}\text { Hardness } \\
\text { change }(-\%)\end{array}$ \\
\hline Dry & 59.5 & 59 & 0.8 \\
Swollen B0 & 54.81 & 49.84 & 9 \\
Swollen B100 & 54.73 & 48.62 & 11 \\
\hline
\end{tabular}

Table 2. Mass of dry and swollen rubbers before and after fatigue test.

\begin{tabular}{llll}
\hline Rubber & $\begin{array}{l}\text { Before } \\
\text { testing }(\mathrm{g})\end{array}$ & $\begin{array}{l}\text { After } \\
\text { testing }(\mathrm{g})\end{array}$ & $\begin{array}{l}\text { Mass } \\
\text { change (-\%) }\end{array}$ \\
\hline Dry & 127.25 & 127.24 & 0 \\
Swollen B0 & 131.69 & 131.17 & 0.39 \\
Swollen B100 & 131.36 & 130.86 & 0.38 \\
\hline
\end{tabular}


B0 and $11 \%$ in swollen B100. It is important to note that this significant change is not observed for the dry rubbers. Hence, this implies that the mechanical loading magnifies the effect of swelling instead of directly decreasing the hardness of rubber. Since mechanical loading does not induce any additional swelling, the chain scission mechanism seems to be the main reason behind the declining values of hardness, from 54.81 and 54.73 (before testing) to 49.84 and 48.62 (after testing) for B0 and B100 swollen rubbers respectively.

\subsection{Stress-stretch response}

The stretch-stress responses of dry and swollen rubber subjected to maximum stretch of 2 at selected number of cycles are plotted in Figure 1. It is observed that the stress decreases for both dry and swollen rubbers as the number of cycles increases and this trend is similar at all maximum stretch levels imposed. Among the swollen rubbers,
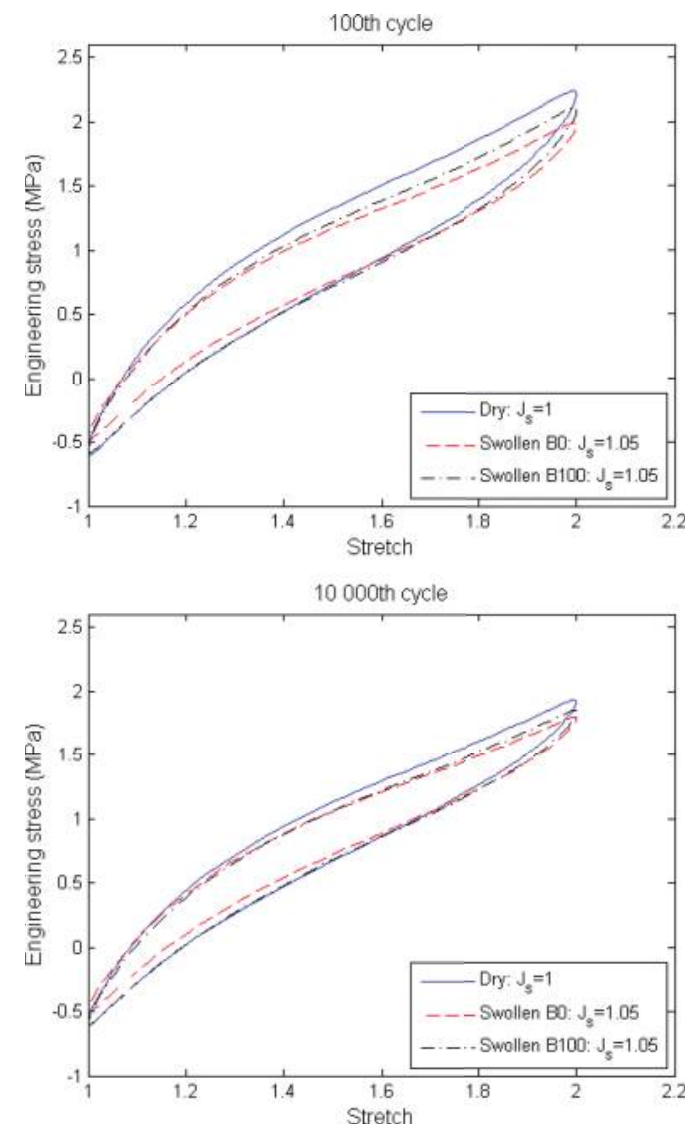

Figure 1. The stretch-stress responses of dry and swollen rubber at maximum stretch of 2 . the stress value is the lowest for the swollen B0 rubber. It is observed that starting from the stabilized cycle loop, the mechanical response is almost similar between the swollen B0 and B100. From this perspective, it is possible that the softening effect is not accountable for the lowest stress value in swollen $\mathrm{B} 0$ rubber. The two possible effects considered for the resultant stretch-stress response are the nature of the swollen rubber due to the effect of diffusion of solvents and the effect from the loading ratio. Note that not all stretch-stress plots at all number of cycles are presented for all loading conditions here since the trend appeared to be similar for each condition.

\subsection{Evolution of peak stress}

In each number of cycles, the peak stresses are identified and the evolutions of the peak stress versus the number of cycles are depicted in Figure 2 for the lowest and highest maximum stretch. Here, the
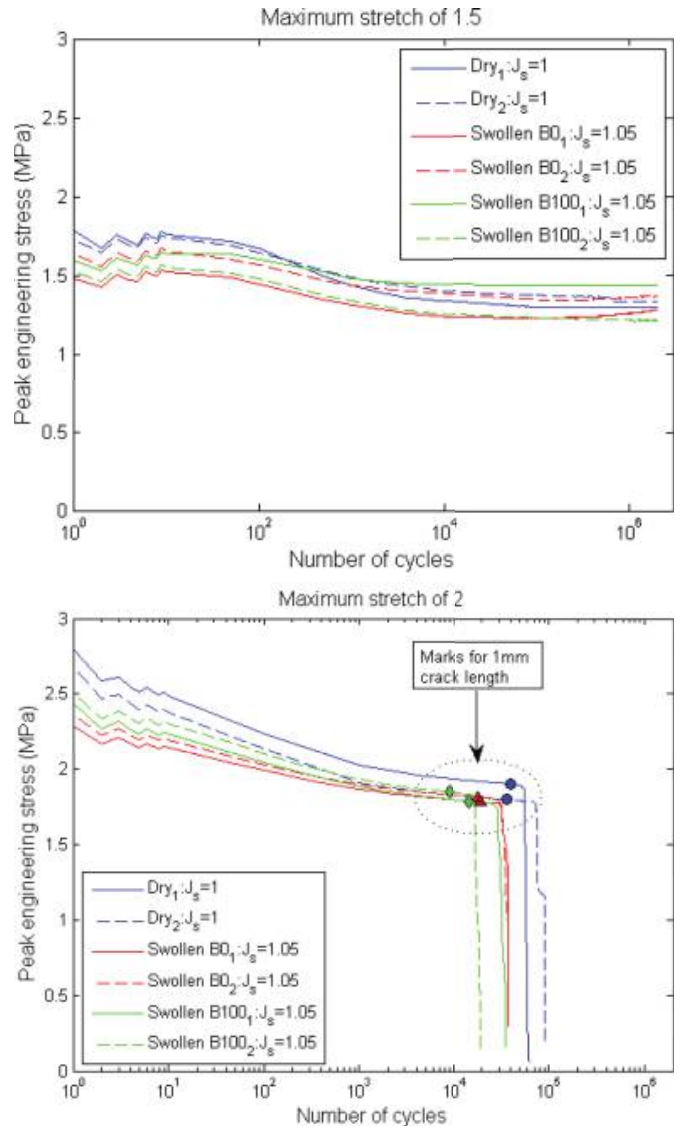

Figure 2. Evolutions of peak stress as a function of number of cycles at selected maximum stretches. 
solid lines represent the results obtained from the first specimen and the dashed lines represent the second one. A particular fluctuation pattern is observed for the first 10 cycles and is purely due to the limitation of the fatigue machine which is unable to reach the imposed maximum stretch value from the very first cycles. Under fatigue loading, the stress value is always highest for the dry rubber, followed by swollen B100 and then finally swollen B0 rubber. This can be explained by the longer amount of time allowed for interactions to occur when the swollen $\mathrm{B} 0$ rubber needed 9 times longer to achieve the same degree of swelling. Unlike the reported works of Benkahla et al. (2013) and Mars (2001), no stabilized response or plateau was observed in the curves in Figure 2.

A mark is drawn onto each curves to illustrate the appearance of the $1 \mathrm{~mm}$ crack at its corresponding number of cycle. It is apparent that the $1 \mathrm{~mm}$ crack emerges at the number of cycles close to rupture, regardless of the maximum stretch level. This indicates that the crack propagates rapidly after the initiation of a $1 \mathrm{~mm}$ crack until it reaches complete rupture.

\subsection{Fatigue lifetime curve}

As a first approach, maximum stretch is chosen as the predictor for the fatigue lifetime. The fatigue lifetime curves is plotted with the maximum stretch versus the number of cycles to failure shown in Figure 3. The end-of-life definition used is the appearance of a $1 \mathrm{~mm}$ crack size and complete rupture. It is to note that no crack appeared at all for both dry and swollen rubbers at the maximum stretch level of 1.5. Hence, no data is plotted Figure 3 at the maximum stretch of 1.5. For this particular case, the end-of-life of the rubber is set to be at 2 million cycles even though no rupture has taken place. Both plots also show the best-fit power-law function to predict the lifetime. The slope for the dry rubber seems to be steeper compared to the swollen rubbers. This result seem to highlight a higher sensitivity of the swollen rubbers towards the imposed loading condition.

In Figure 3, the fatigue lifetime is in the order of dry, swollen B0 and then swollen B100 rubber with the first mentioned having the longest lifetime. Both of these curves exhibit similar trend for the fatigue lifetime. The chemical interaction might be the main consideration for the shortest lifetime of swollen B100 rubber among all. The chemical interaction due to the existing of polarity groups in B100 rubber is non-negligible since none of these polarity effect is found between NBR and B0 solvent. The polarity effect not only contributes to the higher swelling rate, but at the same time initiates the oxidation process induces (Richaud et al.
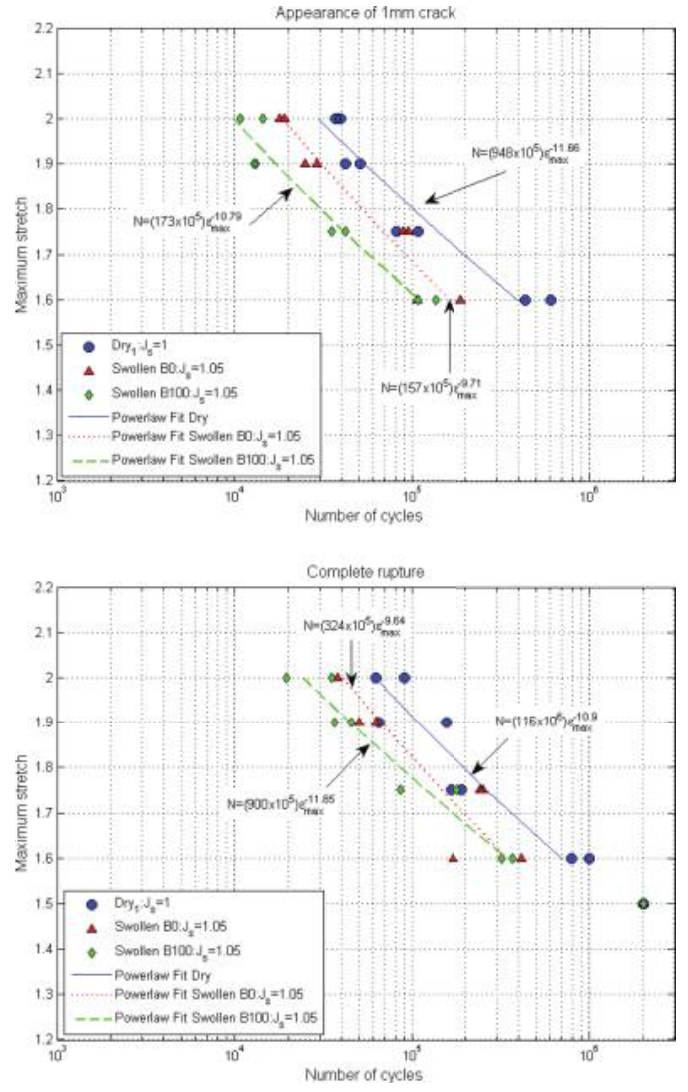

Figure 3. $\lambda$-N curves at appearance of a $1 \mathrm{~mm}$ crack size and complete rupture.

2013). This eventually might have risk the swollen rubber to chain scissoning of the polymer backbone (Haseeb et al. 2010). Besides that, the higher stress values for swollen B100 rubbers shown in Figure 2 deteriorates the lifetime even further.

\subsection{Fractographic analysis}

\subsubsection{At the macroscopic scale}

Two types of fatigue failures were observed upon completion of the fatigue tests for both dry and swollen rubbers, regardless of the loading conditions. One of it exemplify the classical failure reported in the literature, where the rupture occurs in the middle part of the specimen whereas the other one is the bifurcation of cracks. For both of these failures, the crack propagation plane is not perpendicular to the imposed uniaxial loading. This conception is illustrated in Figure 4 where a white dashed line is marked on the specimen to illustrate the crack propagation plane. This is not expected in non-crystallisable rubbers for such 


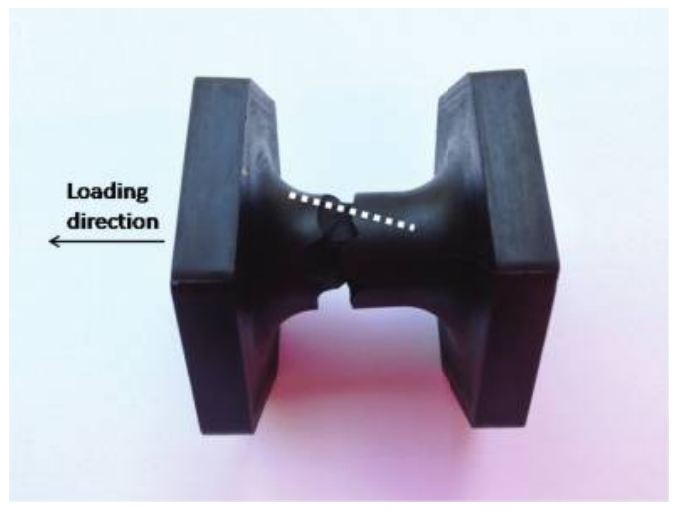

Figure 4. Direction of the crack propagation plane.

Table 3. Features observed in the rubber.

\begin{tabular}{cllll}
\hline Features & $\begin{array}{l}\text { Maximum } \\
\text { stretch }\end{array}$ & Dry & $\begin{array}{l}\text { Swollen } \\
\text { B0 }\end{array}$ & $\begin{array}{l}\text { Swollen } \\
\text { B100 }\end{array}$ \\
\hline $\begin{array}{c}\text { Smooth } \\
\text { surface }\end{array}$ & 1.5 & & & \\
& 1.75 & & $\mathrm{X}$ & $\mathrm{X}$ \\
& 1.9 & & & $\mathrm{X}$ \\
Clouded & 2 & & & $\mathrm{X}$ \\
wool (CW) & 1.5 & & & \\
& 1.75 & $\mathrm{X}$ & $\mathrm{X}$ & $\mathrm{X}$ \\
Crack initiation & 1.9 & $\mathrm{X}$ & $\mathrm{X}$ & $\mathrm{X}$ \\
at surface & 1.5 & $\mathrm{X}$ & $\mathrm{X}$ & $\mathrm{X}$ \\
& 1.75 & $\mathrm{X}$ & $\mathrm{X}$ & $\mathrm{X}$ \\
& 1.9 & $\mathrm{X}$ & $\mathrm{X}$ & $\mathrm{X}$ \\
Rubber & 2 & $\mathrm{X}$ & $\mathrm{X}$ & $\mathrm{X}$ \\
balling & 1.5 & & & \\
& 1.75 & $\mathrm{X}$ & & \\
& 1.9 & & $\mathrm{X}$ & $\mathrm{X}$ \\
& 2 & & $\mathrm{X}$ & $\mathrm{X}$ \\
\hline
\end{tabular}

loading conditions (Le Cam et al. 2014). It seems to indicate that the hollow geometry of the specimen has an effect on the mechanical field at the local scale and especially in the crack tip vicinity. Moreover, the crack initiation at the macroscopic scale was observed at the specimen surface.

\subsubsection{At the microscopic scale}

The observation obtained from the FESEM analysis is summarized in Table 3 to define the crack initiation location, the origin of crack initiation and the specificities of the morphology of the crack propagation zone. The table summarizes the main features observed at the different loading conditions for both dry and swollen rubbers: the presence of smooth surface, presence of clouded wool, crack initiation location and rubber balling.
Figure 5 illustrates the crack initiation site for fracture surface of dry rubber at microscale. The crack initiates at the specimen surface in an almost elliptical shape before propagating into river patterns at the later stage. These patterns are also observed to be similar for swollen rubbers and at all loading conditions. No visible particles were identified for

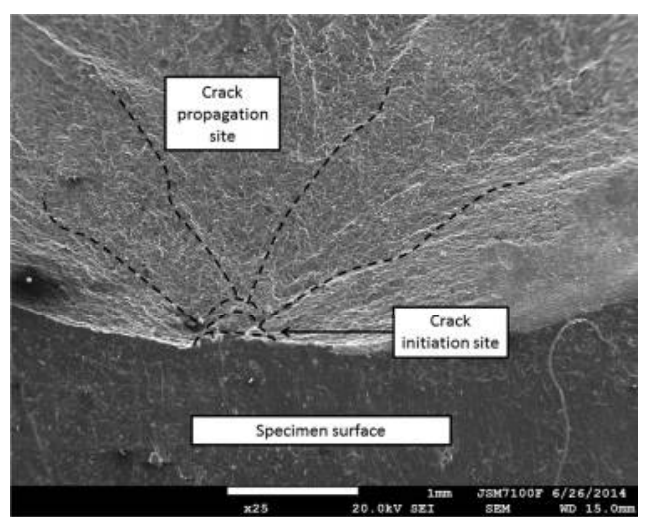

Figure 5. Crack initiation site of dry rubber.
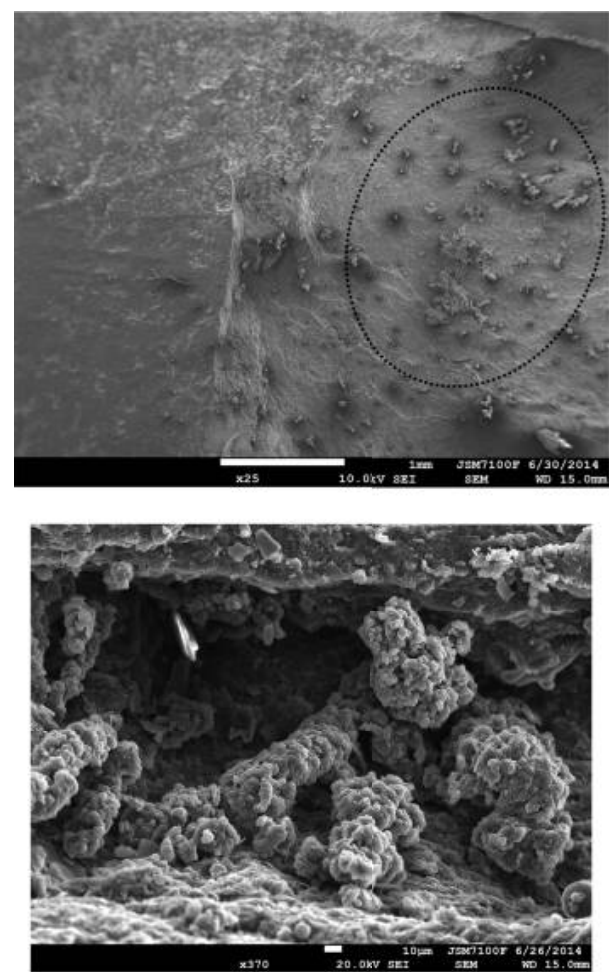

Figure 6. Clouded wool at the surface (Top). Higher magnification of clouded wool (Bottom). 
the defect which leads to crack initiation. Instead, a characteristic pattern of Clouded Wool (CW) at the crack propagation site is observed and shown in Figure 6. The CW exists either in cluster or dispersed form and a clearer illustration of it can be observed in the micrograph at higher magnification. It seemed that the $\mathrm{CW}$ is not bonded to the rubber matrix and is composed of carbon atoms from the result obtained from Energy-dispersive $\mathrm{X}$-ray spectroscopy (EDS). Friction is accounted for the formation of $\mathrm{CW}$ pattern at this stage of investigation. The friction could have arisen from between the generated surfaces during loading, which later released the $\mathrm{CW}$ in cluster or dispersed form towards the crack initiation site. One consideration for this cause is the specimen geometry due to the fact that the crack propagates under a more complex loading condition, instead of a uniaxial tension load. Further investigation has to be carried out to determine the origin of the friction; change in the microstructure at the crack tip and the specimen geometry.

\section{CONCLUSIONS}

In the present work, the fatigue studies of swollen nitrile rubber and was investigated. Experimental works were carried out to compare the mechanical response of dry and swollen rubbers. It was observed that the stress is always highest for dry rubber, followed by swollen B100 and then swollen $\mathrm{B} 0$ rubber. The fatigue lifetime for the swollen B100 rubber appeared to be the shortest at the defined end-of-life i.e. appearance of $1 \mathrm{~mm}$ crack and complete rupture state. FESEM analysis revealed that the crack morphologies are similar for both dry and swollen rubbers regardless of the imposed loading conditions.

\section{ACKNOWLEDGEMENT}

The authors greatly appreciate the financial support from Ministry of Higher Education Malaysia through High Impact Research Grant HIR-MOHE D000008-16001.

\section{REFERENCES}

Alves, S., V. Mello, and J. Medeiros (2013). Palm and soybean biodiesel compatibility with fuel system elastomers. Tribol. Int. 65, 74-80.
Benkahla, J., T. Baranger, and J. Issartel (2013). Fatigue life estimation for an nbr rubber and an expanded polyurethane. Exp. Mech. 53(8), 1383-1393.

Demirbas, A. (2008). Biodiesel: A Realistic Fuel Alternative for Diesel Engines. Springer.

Fazal, M., A. Haseeb, and H. Masjuki (2011). Biodiesel feasibility study: An evaluation of material compatibility; performance; emission and engine durability. Renew. Sust. Energ. Rev. 15, 1314-1324.

Graham, J., R. Striebich, K. Myers, D. Minus, and W. Harrison (2006). Swelling of nitrile rubber by selected aromatics blended in a synthetic jet fuel. Energ. Fuel. 20, 759-765.

Gray, K., L. Zhao, and M. Emptage (2006). Bioethanol. Curr. Opin. Chem. Biol. 10(2), 141-146.

Haseeb, A.S. M.A., M.A. Fazal, M.I. Jahirul, and H.H. Masjuki (2011). Compatibility of automotive materials in biodiesel: A review. Fuel 90(3), 922-931.

Haseeb, A.S.M.A., H.H. Masjuki, C.T. Siang, and M.A. Fazal (2010). Compatibility of elastomers in palm biodiesel. Renew. Energ. 35, 2356-2361.

Le Cam, J.-B., B. Huneau, and E. Verron (2008). Description of fatigue damage in carbon black filled natural rubber. Fatigue Fract. Eng. M. 31(12), 1031-1038.

Le Cam, J.-B., B. Huneau, and E. Verron (2013). Fatigue damage in carbon black filled natural rubber under uni-and multiaxial loading conditions. Int. J. Fatigue.

Le Cam, J.-B., B. Huneau, and E. Verron (2014). Failure analysis of carbon black filled styrene butadiene rubber under fatigue loading conditions. Plast. Rubber Compos. 43(6), 187-191.

Loo, M.S., J.-B. Le Cam, A. Andriyana, E. Robin, and A. Afifi (2015). Fatigue of swollen elastomers. Int. $J$. Fatigue 74, 132-141.

Mars, W.V. (2001). Multiaxial fatigue of rubber. Ph. D. thesis, University of Toledo.

Richaud, E., F. Djouani, B. Fayolle, J. Verdi, and B. Flaconneche (2013). New insights in polymer-biofuels interaction. Oil \& Gas Science and Technology-Revue d'IFP Energies nouvelles.

Saintier, N. (2000). Prévisions de la durée de vie en fatigue $\mathrm{du}$ NR sous chargement multiaxial. Ph. D. thesis, École de Mines de Paris.

Seehra, M., M. Yalamanchi, and V. Singh (2012). Structural characteristics and swelling mechanism of two commercial nitrile-butadiene elastomers in various fluids. Polym. Test 31, 564-571.

Trakarnpruk, W. and S. Porntangjitlikit (2008). Palm oil biodiesel synthesized with potassium loaded calcined hydrotalcite and effect of biodiesel blend on elastomer properties. Renew. Energ. 33, 1558-1563. 